\title{
APPLICATION OF SIMPLIFIED SURFACE ENERGY BALANCE INDEX (S-SEBI) FOR CROP EVAPOTRANSPIRATION USING LANDSAT 8
}

\author{
A. Basit*, R. Z. Khalil, S. Haque \\ Dept. of Remote Sensing and GIS, Institute of Space Technology, Karachi, Pakistan \\ ab.basit93@gmail.com*
}

KEY WORDS: Evapotranspiration, Crop water requirement, S-SEBI

\begin{abstract}
:
Assessment and monitoring of crop water requirement (CWR) or crop evapotranspiration (ETc) over a large spatial scale is the critical component for irrigation and drought management. Due to growing competition and increasing shortage of water, careful utilization of water in irrigation is essential. The usage of water for irrigation/agriculture is a top priority for countries like Pakistan, where the GDP mostly based on agriculture, and its scarcity may affect the crop production. Remote sensing techniques can be used to estimate crop water requirement or crop evapotranspiration which can help in efficient irrigation. Simplified-surface energy balance index (SSEBI) model is used to estimate evapotranspiration (ET) of wheat during 2015-16 growing period in Tando Adam, Sindh. Landsat-8 satellite data for the corresponding years were used. With the help of National Agromet Centre report chart of Crop coefficient $(\mathrm{Kc})$ the CWR, ETc of all phonological stages were estimated. Results indicated that maximum ET and maximum CWR were found in the third leaf to tillering stage with a value of 0.75 and 0.89 respectively. This study will help in managing and monitoring of ET spatial distribution over irrigated crops which results in better irrigation scheduling and water consumption.
\end{abstract}

\section{INTRODUCTION}

Hydrological cycle and the irrigation are mainly controlled by evapotranspiration (ET). ET is the most prominent and valuable factor in irrigation. The accuracy of ET can control water management, irrigation scheduling, and many other factors. Two-thirds of global warming has occurred since the 1980's, which has created temperature fluctuations all over the globe as well as created water inaccessibility. These constant temperature changes may result in droughts which can cause drylands. The usage of water is the top priority for countries like Pakistan where the GDP is mostly based on agriculture, and the lack of water may affect the crop production. Challenges as mentioned earlier call for more effective and technically sound approach for the estimation of crop evapotranspiration (ET). ET is generally pretentious by weather parameters, crop conditions, and management factors and thus often subject to unpredictability over space and time. Temperature variation affecting ET could be measured by various contrivances methods such as PenmanMonteith method, lysimeter, Bowen Ratio Energy Balance (BREB), eddy covariance, etc. However, they prove only point measurements and do not represent spatial heterogeneity in surface and atmospheric conditions. Penman-Monteith method has some difficulty in observations and calculations of aerodynamic parameters and surface resistances for all types of crops; lysimeter is expensive to install and maintain; BREB method is non-reliable during advective periods (Blad \& Rosenberg, 1974), while the eddy covariance technique which has energy balance closure issue due to small areal coverage, shows higher sensitivity for small eddies and needs variety of corrections to obtain final output of fluxes(Clement, Burba, Grelle, Anderson, $\&$ Moncrieff, 2009). These limitations provide a scope of using the new dimension of technology known as 'Remote Sensing' (RS) because it provides a measure of the actual state of vegetation and spatial quality to infer ETc over space and time.
Various RS techniques and models have been proposed over the last few periods for estimation of ETc over cropland and natural ecosystems (Allen, Bastiaanssen, Tasumi, \& Morse, 1998; Carlson, Gillies, \& Schmugge, 1995; Chen, Wang, Jiang, Mao, \& Yu, 2011; Kustas \& Norman, 1999); (Su, 2002); (PATEL, RAKHESH, \& MOHAMMED, 2006);(Allen et al., 1998; ANDERSON et al., 2008; Li et al., 2009; Tang et al., 2011). Most of the remote sensing-energy balance (RS-EB) models are dependent on the field-based as well as weatherbased observations which are dynamic in time. A model which is known as 'Simplified-Surface Energy Balance Index' (SSEBI) has two major advantages over other RS-EB models: (I) no additional meteorological data is needed for energy flux estimation if the surface extremes of vegetation cover and soil moisture are available, (II) this model concerns about the extreme temperature of the dry and wet conditions which varies with changing reflectance values, where other models try to calculate a static value of temperature for dry and wet conditions, both for whole image and for each land use class (Roerink, Su, \& Menenti, 2000). S-SEBI computes ETc using the evaporative fraction $(\Lambda)$ theory and based on parameterization of wet (Maximum ETc ) and dry (minimum ETc ) edge from triangle scatterplot of albedo ( $\alpha$ ) and (LST) (García, Villagarcía, Contreras, Domingo, \& Puigdefábregas, 2007; Gómez, Olioso, Sobrino, \& Jacob, 2005; Mattar et al., 2014; Roerink et al., 2000; Santos, Bezerra, Silva, \& Rao, 2010).

\section{SITE AND DATA DESCRIPTION}

\subsection{Study area}

This study comprises over Tando Adam, Sindh area .Tando Adam is known for its industries and its agriculture; crops raised nearby include sugar-cane, wheat, cotton, bananas, and mangoes.

\footnotetext{
* Corresponding author
} 


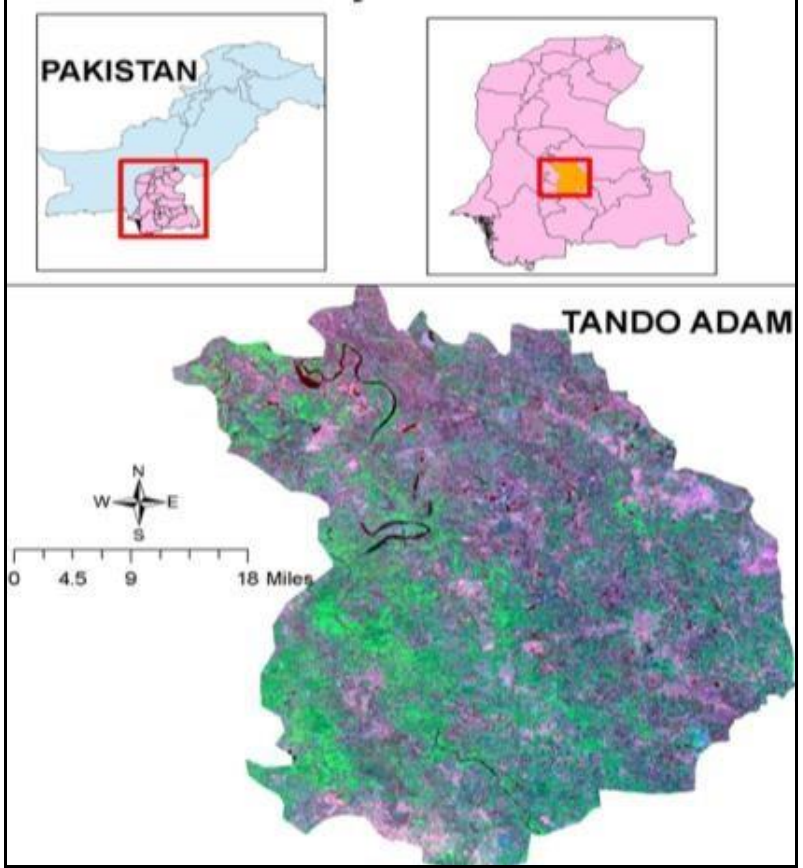

Figure 1. Study Area

\subsection{Satellite data}

The two imaginary Landsat 8 used are Operational Land Imager (OLI) and Thermal Infrared Sensor (TIRS) in the present study. landsat-8 data has 11 spectral bands, where six within the visible and near-infrared (NIR) region and two bands are located in the thermal infrared (TIR) region of the electromagnetic spectrum.

\section{METHODOLOGY}

Using Landsat-8 OLI and TIRS data, the primary purpose of the present study is to frame-work the S-SEBI algorithm and estimate ET. The present section describes steps followed in the pre-processing of remote sensing data, land use/land cover (LULC) classification of the area, parameterization of S-SEBI, estimation of ET.

\subsection{Pre-processing of Landsat-8 image}

Primary corrections such as radiometric and atmospheric corrections are applied and then processed by the Landsat- 8 data. A radiometric correction was done by transforming the Digital Number (DN) values to radiance or reflectance values using standard methodology given by USGS.

\subsection{Calculation of NDVI}

NDVI of all phenological stages were calculated for each month with NIR and Red Bands of Landsat 08 satellite.

$$
N D V I=\frac{\mu_{N I R}-\mu_{R E D}}{\mu_{N I R}+\mu_{R E D}}
$$

\subsection{Parameterization of S-SEBI model}

S-SEBI is a RS-EB model to estimate surface energy fluxes from remote sensing measurements. For estimation of ET we calculate evaporative fraction from remote sensing using surface reflectance and LST from dry and wet pixels, the model was developed by (Roerink et al., 2000). This model has been already tested and validated globally with the in situ flux measurements (García et al., 2007; Gómez et al., 2005; Jin, Wan, \& Su, 2005; Mattar et al., 2014; Santos et al., 2010; Sobrino, Gómez, JiménezMuñoz, Olioso, \& Chehbouni, 2005). The surface energy balance in a generalized form can be written as (Allen et al., 1998):

$$
\mathrm{Rn}=\mathrm{H}+\lambda \mathrm{E}+\mathrm{G}
$$

Where, $\mathrm{Rn}$ is the net radiation flux (Wm-2); $\mathrm{H}$ is the sensible heat flux $(\mathrm{Wm}-2), \lambda \mathrm{E}$ is the latent heat flux $(\mathrm{Wm}-2)$ and $\mathrm{G}$ is the soil surface heat flux $(\mathrm{Wm}-2)$. This model is applied in the present for regional estimation. Normalized Difference Vegetation Index (NDVI) and surface albedo were estimated from visible, NIR and SWIR bands Landsat-8 OLI. Surface albedo $(\alpha)$ was retrieved by applying narrowband to broadband conversion as per the method proposed by Smith (2010). The LST, another important parameter in the estimation of $\Lambda$ using SSEBI was derived by applying single-channel LST retrieval method suggested by (Sobrino et al., 2005)on the 10th band (TIR band) of Landsat- 8 data. The known prior method of surface emissivity $\left(\varepsilon_{0}\right)$ estimation was used to generate $\varepsilon 0$ maps using NDVI as primary inputs. The Rn which is the vector sum of the difference in the incoming shortwave radiation (RS $\downarrow$ ) and the reflected shortwave radiation (RS $\uparrow$ ), the downward atmospheric longwave (RL $\downarrow$ ) and the surface-emitted longwave radiation $(\mathrm{RL} \uparrow)$ can be expressed as:

$$
\mathrm{Rn}=(1-\alpha) \cdot \mathrm{RS} \downarrow+\mathrm{RL} \downarrow-\mathrm{RL} \uparrow-(1-\varepsilon 0) \cdot \mathrm{RL} \downarrow
$$

All these components in this equation were estimated to find out the observed meteorological data from the study area via Landsat-8. The energy to heat up the soil is represented by the sole letter $\mathrm{G}$. The ratio based empirical relation of $\mathrm{G}$ proposed by (Bastiaanssen, 2000)can be expressed as:

$$
\frac{G}{\mathrm{Rn}}=\frac{T_{s}\left(0.0038 \times \alpha+0.0074 \times \alpha^{2}\right)\left(1-0.98 \times N D V I^{4}\right)}{\alpha}
$$

Location and time of image acquisition are represented by the letter $\mathrm{T}$. The estimation of the $\mathrm{H}$ is the most complex component, in this equation. In S-SEBI, the $\mathrm{H}$ and $\lambda \mathrm{E}$ are not calculated separately, the combined value of these two fluxes in the form of $\Lambda$ is calculated as:

It is observed by (Roerink et al., 2000)that if the surface reflectance is plotted against the surface temperature, at low reflectance, the with increasing reflectance surface temperature is less or more constant specifically for saturated water surfaces like land irrigation and open water.

Two extreme surface reflectance-to-surface temperature relationships can be established, is used for computing Evaporating Fraction $(\Lambda)$ by two extreme pixels (wet and dry pixel). In the case of a wet pixel, $\mathrm{H}$ can be assumed as zero so $\lambda \mathrm{E}_{\max }$ can be estimated by subtracting $\mathrm{G}$ from Rn (i.e. $\lambda \mathrm{E}_{\max }=$ $\mathrm{Rn}-\mathrm{G})$. While at the dry pixel $\mathrm{H}$ will be the highest $\left(\mathrm{H}_{\max }\right)$, which can be estimated by subtracting the $G$ from $R n$ (i.e. $H_{\max }$ $=\mathrm{Rn}-\mathrm{G})$. In such case the $\Lambda$ can be expressed as:

$$
\Lambda=\frac{\left(T_{H}-T_{S}\right)}{T_{H}-T_{L E}}
$$


Dry pixels and wet pixels are defined by the letters $\mathrm{TH}$ and TLE. Dry edge (radiation controlled), wet edge (evaporation controlled).

$$
T_{H}=a_{H}+b_{H} \times \alpha
$$

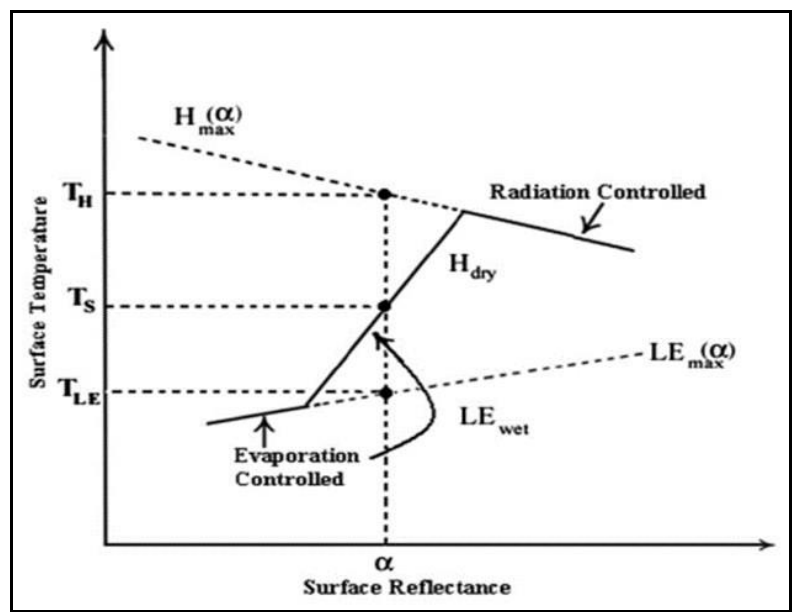

Figure 2. Surface reflectance-to-surface temperature relationship

$\mathrm{a}_{\mathrm{H}}, \mathrm{b}_{\mathrm{H}}, \mathrm{a}_{\lambda \mathrm{E}}$ and $\mathrm{b}_{\lambda \mathrm{E}}$ are empirical coefficients estimated from the scatter plot between LST and $\alpha$ over study area for each satellite image. Substituting Equations (6) and (7) in Equation

(5) the $\Lambda$ can be estimated as:

$$
T_{\lambda \mathrm{E}}=a_{\lambda \mathrm{E}}+b_{\lambda \mathrm{E}} \times \alpha
$$

Once $\Lambda$ is determined $\lambda \mathrm{E}$ is calculated as;

$$
\Lambda=\frac{\lambda \mathrm{E}}{\lambda \mathrm{E}-H}=\frac{\lambda \mathrm{E}}{R_{n}-G_{0}}
$$

By this formula.

Then we calculated $\lambda E$ in $\mathrm{mm} /$ hour by this formula:

$$
E T_{I N S T}=\frac{3600 \times \lambda \mathrm{E}}{\lambda}
$$

Where $\lambda=2260000 \mathrm{~J} / \mathrm{kg}$

\subsection{Calculation of Crop Water Requirement (CWR)}

After determining ET crop water requirement (CWR) can be predicted using the appropriate crop-coefficient $(\mathrm{Kc})$. With the help of National Agromet Centre kc chart. The formula for calculating the CWR for ET crop is:

$$
\begin{gathered}
E T_{\text {CROP }}=K_{c} \times E T_{o} \\
\text { Or } \\
C W R=K_{c} \times E T_{o}
\end{gathered}
$$

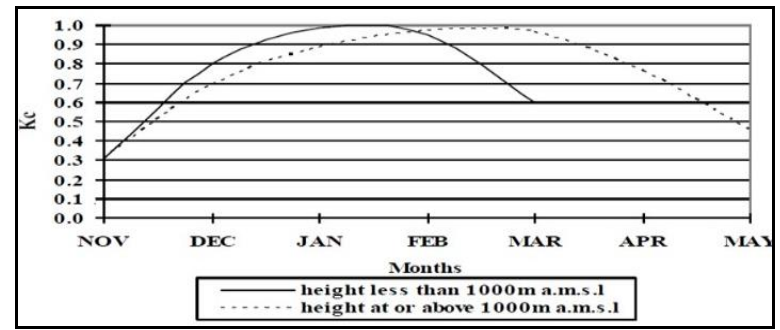

Figure 3. Kc Chart

\section{RESULTS}

The study results consist on NDVI, ET and CWR based phenological stages of wheat crop which used determine the area for wheat crop, water stress conditions at different time periods and finally the estimates of CWR.

\subsection{Normalized Difference Vegetation Index (NDVI)}

From the observation of NDVI, we get the different vegetation index from sowing to full maturity. Figure 4 and 5 presents the sowing to emergence NDVI of wheat is just growing with the value of 0.3 which is the minimum value. In the emergence of the third leaf, the value of NDVI is 0.34 . In the third leaf to tillering, the value of NDVI is 0.45 . In tillering to shooting the value, NDVI is 0.48 . In shooting to heading the value of NDVI is 0.59 which is maximum. In flowering to milk maturity 0.56 . In milk maturity, to wax maturity the value is 0.31 . In wax maturity, to full maturity, the value of NDVI is 0.31 . The graphical representation shows the values of NDVI index wheat crop seasons maturity, the higher the value means the higher the crop of wheat in that month.

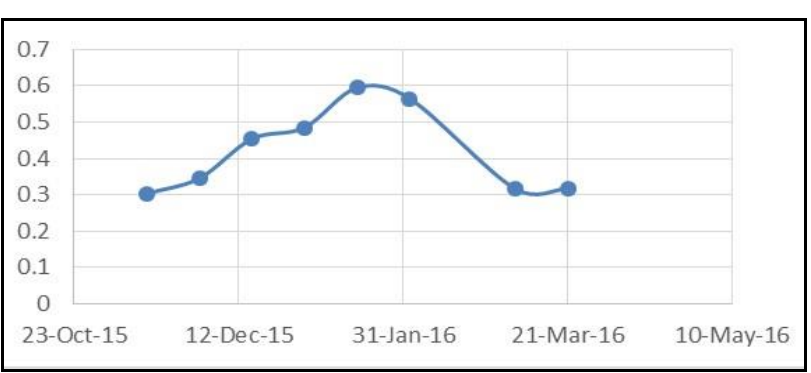

Figure 4. NDVI Graph

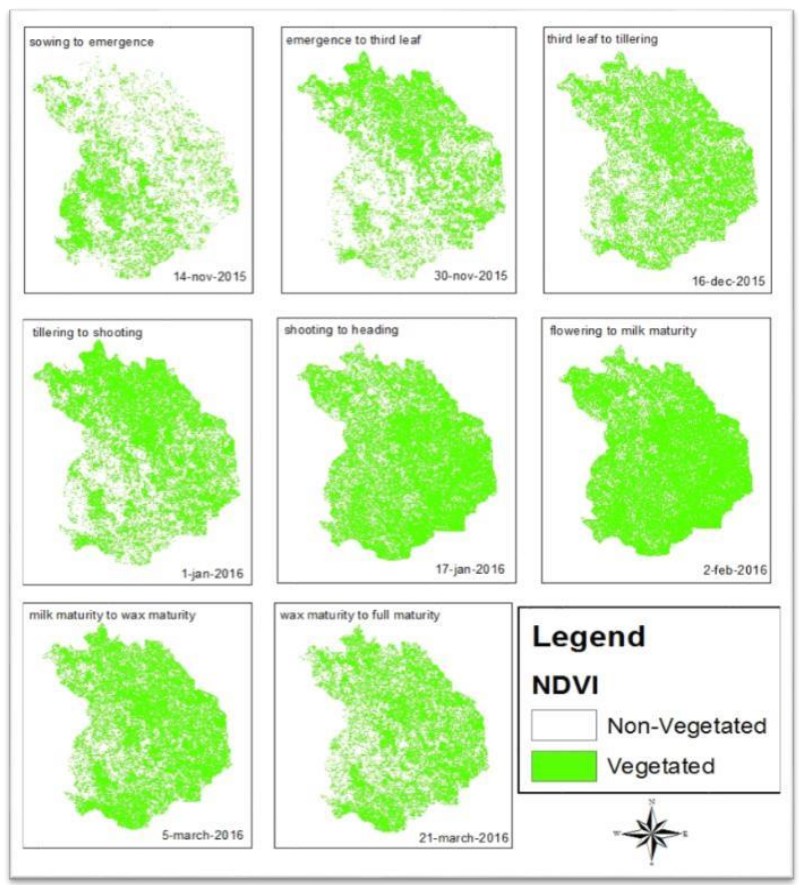

Figure 5. NDVI Phenological Stages

\subsection{Evapotranspiration}

Different vegetation indices showed the different season of wheat which help out in the determination of ET. Figure 6 and 7 shows the mapped and graphical ET values, the higher the 
value, the higher the evapotranspiration on the month of that crop. In sowing to emergence, the ET of that period is low with a value of 0.19 . In the emergence of the third leaf, the value of ET is 0.42 . In the third leaf to tillering, ET is maximum with a value of 0.75 . In tillering to shooting the value ET is 0.45 . In shooting to heading the value of ET is 0.38 In flowering to milk maturity, the value is 0.55 . In milk maturity, to wax maturity the value is 0.39 . In wax maturity, to full maturity, the value is 0.32 .

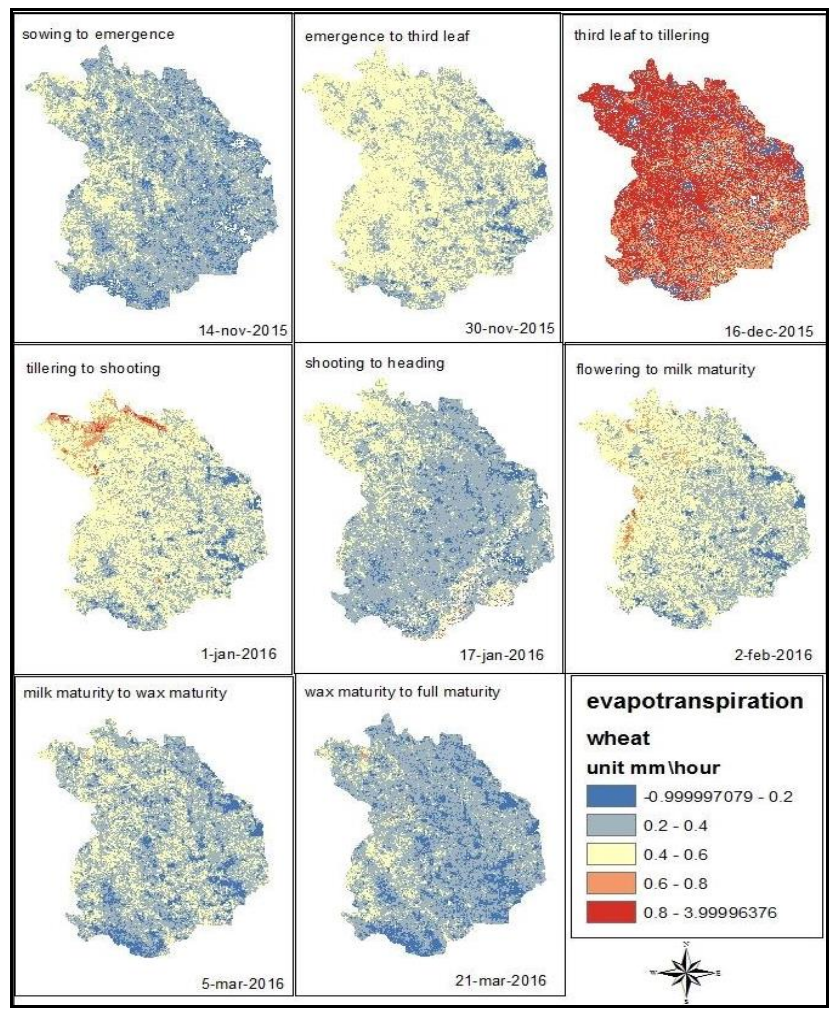

Figure 6. ET Phonological Stages

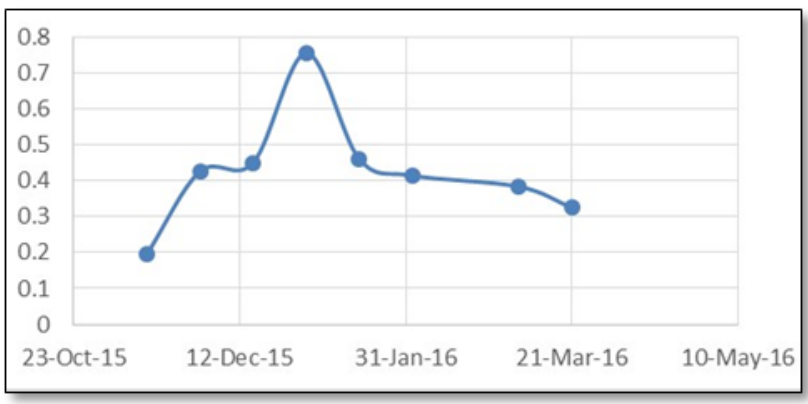

Figure 7. ET at different phenological stages

\subsection{Crop water requirement $(\mathrm{CWR})$}

In sowing to emergence, the CWR of wheat is 0.15 . In emergence of the third leaf, the value of CWR is 0.34 . In the third leaf to tillering, the value is 0.89 which is maximum of CWR. In tillering to shooting the value is 0.35 . In shooting to heading the value is 0.39 . In flowering to milk maturity, the value is 0.41 . In milk maturity, to wax maturity the value is 0.21 . In wax maturity, to full maturity, the value is 0.14 .

It is clear to find out the selective months for water requirement throughout the wheat phenology. The higher the value, the higher the CWR.

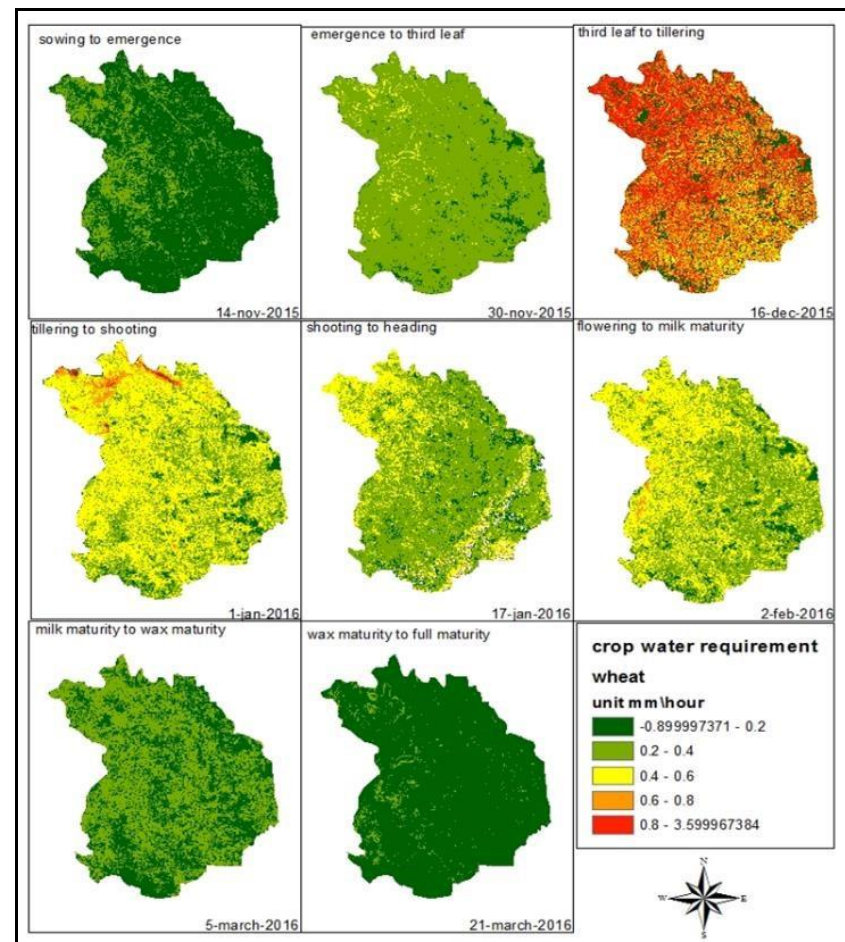

. Figure 8. CWR Phenological Stages

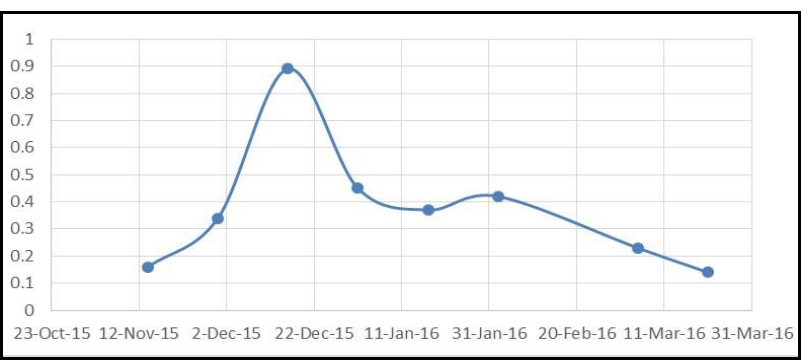

Fiqure 9. CWR OR Kc Graph

\section{CONCLUSION}

In this study, we explored the NDVI values, ET values of wheat crops at different phenological stages. With the help of $\mathrm{kc}$ values published by National Agromet Centre, we also calculated CWR of all phenological stages of wheat. The maximum NDVI values were found in flowering to milk maturity stage.the maximum ET was found in the third leaf to tillering stage the maximum value of CWR was found in the third leaf to tillering stage. This study will help to manage and monitor the spatial distribution of ET over irrigated crops which results in better irrigation scheduling and water consumption.

\section{REFERENCES}

Allen, R. G., Bastiaanssen, W., Tasumi, M., \& Morse, A. (1998). Evapotranspiration on the watershed scale using the SEBAL model and Landsat images. In 2001 ASAE Annual Meeting (p. 1).

ANDERSON, M., NORMAN, J., KUSTAS, W., HOUBORG, R., STARKS, P., \& AGAM, N. (2008). A thermal-based remote sensing technique for routine mapping of landsurface carbon, water and energy fluxes from field to regional scales. Remote Sensing of Environment, 
112(12),

$4227-4241$ https://doi.org/10.1016/j.rse.2008.07.009

Bastiaanssen, W. G. M. (2000). SEBAL-based sensible and latent heat fluxes in the irrigated Gediz Basin, Turkey. Journal of Hydrology, 229(1-2), 87-100.

Blad, B. L., \& Rosenberg, N. J. (1974). Lysimetric calibration of the Bowen ratio-energy balance method for evapotranspiration estimation in the central Great Plains. Journal of Applied Meteorology, 13(2), 227-236.

Carlson, T. N., Gillies, R. R., \& Schmugge, T. J. (1995). An interpretation of methodologies for indirect measurement of soil water content. Agricultural and Forest

Meteorology, 77(3-4), 191-205. https://doi.org/10.1016/0168-1923(95)02261-U

Chen, J., Wang, C., Jiang, H., Mao, L., \& Yu, Z. (2011). Estimating soil moisture using Temperature-Vegetation Dryness Index (TVDI) in the Huang-huai-hai (HHH) plain. International Journal of Remote Sensing, 32(4), $1165-1177$. https://doi.org/10.1080/01431160903527421

Clement, R. J., Burba, G. G., Grelle, A., Anderson, D. J., \& Moncrieff, J. B. (2009). Improved trace gas flux estimation through IRGA sampling optimization. Agricultural and Forest Meteorology, 149(3-4), 623638.

García, M., Villagarcía, L., Contreras, S., Domingo, F., \& Puigdefábregas, J. (2007). Comparison of Three Operative Models for Estimating the Surface Water Deficit Using

ASTER Reflective and Thermal Data. Sensors, 7(6), 860

883. https://doi.org/10.3390/s7060860

Gómez, M., Olioso, A., Sobrino, J. A., \& Jacob, F. (2005). Retrieval of evapotranspiration over the Alpilles/ReSeDA experimental site using airborne POLDER sensor and a thermal camera. Remote Sensing of Environment, 96(3-4), 399-408.

Jin, X., Wan, L., \& Su, Z. (2005). Research on evaporation of Taiyuan basin area by using remote sensing. Hydrology and Earth System Sciences Discussions, 2(1), 209-227.

Kustas, W. P., \& Norman, J. M. (1999). Evaluation of soil and vegetation heat flux predictions using a simple twosource model with radiometric temperatures for partial canopy cover. Agricultural and Forest Meteorology, 94(1), 13- 29.

Li, Z.-L., Tang, R., Wan, Z., Bi, Y., Zhou, C., Tang, B., ... Zhang, X. (2009). A Review of Current Methodologies for Regional Evapotranspiration Estimation from Remotely

Sensed Data. Sensors, 9(5), 3801-3853. https://doi.org/10.3390/s90503801

Mattar, C., Franch, B., Sobrino, J. A., Corbari, C., JiménezMuñoz, J. C., Olivera-Guerra, L., ... Mancini, M. (2014).

Impacts of the broadband albedo on actual evapotranspiration estimated by S-SEBI model over an agricultural area. Remote Sensing of Environment, 147, 23-42. https://doi.org/10.1016/j.rse.2014.02.011

PATEL, N. R., RAKHESH, D., \& MOHAMMED, A. J. (2006). Mapping of regional evapotranspiration in wheat using Terra/MODIS satellite data. Hydrological Sciences

Journal $51(2)$,

$325-335$.
Roerink, G. J., Su, Z., \& Menenti, M. (2000). S-SEBI: A simple remote sensing algorithm to estimate the surface energy balance. Physics and Chemistry of the Earth, Part B: Hydrology, Oceans and Atmosphere, 25(2), 147-157.

Santos, C. A. C. dos, Bezerra, B. G., Silva, B. B. da, \& Rao, T. V. R. (2010). Assessment of daily actual evapotranspiration with SEBAL and S-SEBI algorithms in cotton crop. Revista Brasileira de Meteorologia, 25(3),

383-392.

77862010000300010

Sobrino, J. A., Gómez, M., Jiménez-Muñoz, J. C., Olioso, A., \& Chehbouni, G. (2005). A simple algorithm to estimate evapotranspiration from DAIS data: Application to the DAISEX campaigns. Journal of Hydrology, 315(1-4), 117-125. https://doi.org/10.1016/j.jhydrol.2005.03.027

$\mathrm{Su}, \mathrm{Z}$. (2002). The Surface Energy Balance System (SEBS) for estimation of turbulent heat fluxes. Hydrology and Earth System Sciences, 6(1), 85-100. https://doi.org/10.5194/hess-6-85-2002

Tang, R., Li, Z.-L., Jia, Y., Li, C., Sun, X., Kustas, W. P., \& Anderson, M. C. (2011). An intercomparison of three remote sensing-based energy balance models using Large Aperture Scintillometer measurements over a wheat-corn production region. Remote Sensing of Environment, 115(12), $3187-3202$. https://doi.org/10.1016/j.rse.2011.07.004 https://doi.org/10.1623/hysj.51.2.325 